\title{
DESAFIOS PARA O ENSINO DE TEATRO NO ENSINO SUPERIOR: \\ políticas de inclusão e trajetória de vida
}

\author{
DESAFÍOS PARA LA ENSEÑANZA DE TEATRO EN LA \\ ENSENAANZA SUPERIOR: \\ políticas de inclusión y trayectoria de vida
}

\section{CHALLENGES FOR THEATER TEACHING IN HIGHER EDUCATION: inclusion policies and life trajectory}

\author{
Ricardo Carvalho de Figueiredo ${ }^{1}$
}

\begin{abstract}
RESUMO
No presente artigo retomo alguns desafios colocados para a universidade pública, tal como a heterogeneidade do público ingressante no curso de graduação em Teatro, através das políticas de inclusão. Trago a história de um educador negro e como a abordagem da história de vida nos auxiliou no modo de potencializar sua história no encontro com estudantes da educação básica. Conclui-se entendendo que a trajetória de vida se mostrou potente para a nova adequação curricular das licenciaturas.
\end{abstract}

PALAVRAS-CHAVE: Formação de professores, História de vida,

Pedagogia do Teatro, PIBID

\section{RESUMEN}

En el presente artículo retomo algunos desafíos que están colocados para la universidad pública, tal como la heterogeneidad del público ingresante en el curso de graduación en Teatro, a través de las políticas de inclusión. Traigo la historia de un educador negro y cómo el abordaje de la historia de vida nos ayudó en el modo de potenciar su historia en el encuentro con estudiantes de la educación básica. Se concluye entendiendo que la trayectoria de vida se mostró como potente para la nueva adecuación curricular del profesorado en Teatro.

PALABRAS CLAVE: Formación de profesores, Historia de la vida, Pedagogía del teatro, PIBID

\begin{abstract}
In this article I return to the challenges posed to the public university, as well as the heterogeneity of the public entering the undergraduate course in Theater, through inclusion policies. I bring the story of a black educator and how the approach to life history has helped us to leverage its history in meeting with students of basic education. It concludes by understanding
\end{abstract}

\footnotetext{
${ }_{1}^{1}$ Professor adjunto do curso de graduação em Teatro e do Programa de Pós-Graduação em Artes da Universidade Federal de Minas Gerais. E-mail: ricaredo@yahoo.com.br
} 
that the life trajectory has proved potent for the new curricular adaptation of the degrees.

KEYWORDS: Teacher training, Life history, Pedagogy of Theater, PIBID

\section{Introdução}

O texto ora apresentado é oriundo da minha atuação enquanto coordenador do PIBID Teatro na UFMG. Na condição de formador de outros formadores, a experiência do PIBID se mostrou rica no campo da formação de professores por aproximar o professor em formação da realidade da docência, já que o licenciando acompanhava o dia a dia escolar e o trabalho do professor supervisor.

Antes de falar da experiência de um educador em formação, apresento brevemente como a UFMG tem se adequado à política de inclusão e que,

Apresento a seguir alguns dados que compõem o rol de cursos de teatro disponíveis na capital mineira e que, os alunos ingressantes na graduação, em grande parte, foram participantes.

\section{Cursos de Teatro disponíveis em Belo Horizonte}

Atualmente a cidade de Belo Horizonte possui três cursos técnicos de formação de atores: o Teatro Universitário (TU) da UFMG, o Centro de Formação Artística e Tecnológica da Fundação Clóvis Salgado (CEFART) e o Teatro da Pontifícia Universidade Católica de Minas Gerais (PUCMinas). Além dos cursos técnicos, dispomos, na cidade, de cursos livres gratuitos de teatro como na Escola Livre de Arte (ELA, antigo Arena da Cultura) da Prefeitura de Belo Horizonte; o programa Valores de Minas do Governo Estadual; e grupos de teatro que mantém centros culturais com oficinas, tal como o Galpão Cine Horto e a ZAP (Zona de Arte da Periferia) 18, por exemplo. 
Desse modo, nossos alunos, em sua maioria, advêm dos cursos existentes na cidade de Belo Horizonte, cursos livres tais como oficinas, participação em projetos sociais, ONGs, grupos de teatro amador, igreja etc.

$\mathrm{Ou}$ seja, ainda temos uma quantidade significativa de estudantes que advém de experiências teatrais diversas, principalmente em cursos disponibilizados na capital mineira - o que é bastante diferente em cidades do interior de Minas Gerais.

Em conversas diagnósticas, durante o início de disciplinas que ministro, pergunto aos alunos da graduação sobre suas experiências teatrais que antecedem o ingresso na universidade. Grande parte dos estudantes tiveram experiência teatral antes do ingresso no ensino superior, em sua maioria cursados nas instituições mencionadas acima. Quanto ao teatro na educação básica, no tempo curricular da aula de Arte/Teatro, são raríssimas as experiências mencionadas e, quando acontecem, geralmente foram oportunizadas por professores de outras disciplinas em propostas do uso do teatro, em uma concepção essencialista/instrumental (EISNER, 1972), para ensinar/fixar outro conteúdo.

Há, conforme apresentarei a seguir, um grau de exigência em nosso processo seletivo, que ainda traz a prova de habilidade específica para o candidato que deseja cursar a graduação em Teatro na Universidade Federal de Minas Gerais. Exigência esta que não se aproxima das oportunidades ofertadas na educação básica. Infiro, desse modo, que grande parte dos estudantes da graduação em Teatro advém de cursos livres ou técnicos de formação de ator e aqueles cidadãos que não podem custear (seja através da mensalidade e/ou do deslocamento) um curso extraescolar de teatro, tende a ser excluído da possibilidade de cursar teatro no ensino superior. 
Das vagas: prova de habilidade específica vestibular 2018 da UFMG

\author{
Quadro 1
}

Cursos de graduação oferecidos em Belo Horizonte, pela UFMG, com provas de habilidades específicas

\begin{tabular}{|c|c|c|c|c|c|c|c|c|c|c|c|c|c|c|}
\hline \multirow[b]{4}{*}{ Curso } & \multicolumn{4}{|c|}{ Total Geral de Vagas } & \multicolumn{9}{|c|}{ Vagas Reservadas para a Rede Pública de Ensino } & \multirow[b]{4}{*}{$\begin{array}{c}\text { Total } \\
\text { de } \\
\text { Vagas } \\
\text { para } \\
\text { Ampla } \\
\text { Concor } \\
\text {-rência }\end{array}$} \\
\hline & \multirow[b]{3}{*}{ Turno } & \multirow{3}{*}{\begin{tabular}{|l|}
$\mathbf{T}$ \\
$\mathbf{O}$ \\
$\mathbf{T}$ \\
$\mathbf{A}$ \\
$\mathbf{L}$ \\
\\
$\mathbf{G}$ \\
$\mathbf{E}$ \\
$\mathbf{R}$ \\
$\mathbf{A}$ \\
$\mathbf{L}$
\end{tabular}} & \multirow{2}{*}{\multicolumn{2}{|c|}{$\begin{array}{c}\text { Distribuição } \\
\text { Prevista* }\end{array}$}} & \multicolumn{4}{|c|}{$\begin{array}{c}\text { Renda mensal de até } 1,5 \text { salário } \\
\text { mínimo per capita }\end{array}$} & \multicolumn{4}{|c|}{ Independente da Renda Familiar } & \multirow[b]{3}{*}{$\begin{array}{c}\text { Total } \\
\text { de } \\
\text { Vagas } \\
\text { Reser- } \\
\text { vadas }\end{array}$} & \\
\hline & & & & & Com De & ficiência & & & Com De & ficiência & & & & \\
\hline & & & $\begin{array}{c}1^{\circ} \\
\text { Semes } \\
\text { tre }\end{array}$ & $\begin{array}{c}2^{\circ} \\
\text { Semes- } \\
\text { tre }\end{array}$ & $\begin{array}{c}\text { Auto } \\
\text { decla- } \\
\text { rados } \\
\text { negros } \\
\text { (pretos } \\
\text { ou } \\
\text { pardos) } \\
\text { ou } \\
\text { indige- } \\
\text { nas }\end{array}$ & \begin{tabular}{|c|} 
Não \\
decla- \\
rados \\
negros \\
(pretos \\
ou \\
pardos) \\
ou \\
indige- \\
nas
\end{tabular} & $\begin{array}{c}\text { Auto } \\
\text { decla- } \\
\text { rados } \\
\text { negros } \\
\text { (pretos } \\
\text { ou } \\
\text { pardos) } \\
\text { ou } \\
\text { indige- } \\
\text { nas }\end{array}$ & $\begin{array}{c}\text { Não } \\
\text { decla- } \\
\text { rados } \\
\text { negros } \\
\text { (pretos } \\
\text { ou } \\
\text { pardos) } \\
\text { ou } \\
\text { indige- } \\
\text { nas }\end{array}$ & $\begin{array}{c}\text { Auto } \\
\text { decla- } \\
\text { rados } \\
\text { negros } \\
\text { (pretos } \\
\text { ou } \\
\text { pardos) } \\
\text { ou } \\
\text { indige- } \\
\text { nas }\end{array}$ & \begin{tabular}{|c|} 
Não \\
decla- \\
rados \\
negros \\
(pretos \\
ou \\
pardos) \\
ou \\
indige- \\
nas \\
\end{tabular} & $\begin{array}{c}\text { Auto } \\
\text { decla- } \\
\text { rados } \\
\text { negros } \\
\text { (pretos } \\
\text { ou } \\
\text { pardos) } \\
\text { ou } \\
\text { indige- } \\
\text { nas }\end{array}$ & $\begin{array}{c}\text { Não } \\
\text { decla- } \\
\text { rados } \\
\text { negros } \\
\text { (pretos } \\
\text { ou } \\
\text { pardos) } \\
\text { ou } \\
\text { indige- } \\
\text { nas }\end{array}$ & & \\
\hline $\begin{array}{c}\text { Artes } \\
\text { Visuais }\end{array}$ & Diurno & 80 & 40 & 40 & 3 & 3 & 8 & 6 & 3 & 3 & 8 & 6 & 40 & 40 \\
\hline $\begin{array}{c}\text { Cinema de } \\
\text { Animação e } \\
\text { Artes } \\
\text { Digitais } \\
\end{array}$ & Noturno & 40 & 40 & - & 2 & 1 & 4 & 3 & 2 & 1 & 4 & 3 & 20 & 20 \\
\hline $\begin{array}{c}\text { Dança - } \\
\text { Licenciatura }\end{array}$ & Noturno & 20 & -- & 20 & 1 & 1 & 2 & 1 & 1 & 1 & 2 & 1 & 10 & 10 \\
\hline $\begin{array}{l}\text { Design de } \\
\text { Moda }\end{array}$ & Noturno & 45 & 45 & - & 2 & 2 & 5 & 3 & 2 & 2 & 4 & 3 & 23 & 22 \\
\hline $\begin{array}{c}\text { Música } \\
\text { Bacharelado } \\
\text { (') }\end{array}$ & $\begin{array}{l}\text { Diurno } \\
\text { Noturno }\end{array}$ & 76 & 76 & - & 26 & 1 & 3 & 0 & 9 & 1 & 2 & 0 & 42 & 34 \\
\hline $\begin{array}{c}\text { Música - } \\
\text { Licenciatura }\end{array}$ & Noturno & 30 & 30 & - & 2 & 1 & 3 & 2 & 1 & 1 & 3 & 2 & 15 & 15 \\
\hline Teatro & Diurno & 40 & 20 & 20 & 2 & 1 & 4 & 3 & 2 & 1 & 4 & 3 & 20 & 20 \\
\hline $\begin{array}{c}\text { Total de } \\
\text { vagas }\end{array}$ & & 331 & 251 & 80 & 38 & 10 & 29 & 18 & 20 & 10 & 27 & 18 & 170 & 161 \\
\hline
\end{tabular}

Fonte: https://www.ufmg.br/copeve/Arquivos/2017/vest consolidado ufmg2018.pdf Acessado em 10/04/2018.

Conforme quadro anterior, observa-se que o curso de Teatro da UFMG, tal como Artes Visuais, Cinema de Animação e Artes Digitais, Dança e Música, ainda mantém a prova de habilidade específica, diferente de cursos de graduação de Teatro em outras universidades públicas do país. Essa etapa do processo seletivo prevê duas provas compreendidas em: Atuação e Audição Didática Coletiva.

A prova de Atuação é composta por duas questões. Na de Atuação Cênica, com valor de 80,0 pontos, o candidato é avaliado a partir de um monólogo, preparado previamente; a questão de Canto Cênico, valorada com 20,0 pontos, o candidato deve cantar, individualmente, uma canção com acompanhamento de um playback, fornecido pela equipe do vestibular. 
A prova de Audição Didática Coletiva é composta de três questões, sendo: Improvisação Corporal, no valor de 25,0 pontos; Canto e movimento, no valor de 30 pontos e Improvisação em grupo no valor de 45,0 pontos. A primeira questão versa sobre os princípios do movimento em que o candidato deve compor uma sequência de movimentos a partir de fatores (peso, velocidade e espaço) sorteados pela banca. Na questão do Canto e movimento há uma demonstração, por um instrutor específico, de uma sequência de movimentos em que o candidato, já conhecendo uma canção disponibilizada no site do vestibular, deve cantar e movimentar-se de acordo com o demonstrado. E na terceira questão desta prova, Improvisação em grupo, o candidato deve improvisar a partir de estímulos dados por um instrutor.

Voltando à tabela apresentada acima, que está em consonância com a Lei de Cotas (Lei 12.711/2012) e prevê a reserva de vagas no vestibular das IFES a partir dos três critérios (origem de escola pública, renda familiar, cor/raça), a UFMG está de acordo com a Lei e, também, o acesso desses jovens ao curso de graduação em Teatro, ocorre.

Se, em um momento anterior, a prova de habilidade específica era muito parecida com a atual, porém sem a Lei de Cotas (2012), o curso em questão excluía os estudantes da educação básica que não tinham tido acesso aos códigos teatrais exigidos nesta etapa do vestibular. Mas os ingressantes no curso vinham, em sua maioria, de cursos de iniciação teatral que dava uma base, ainda que mínima, para a formação em teatro no nível superior.

Com a implementação da referida Lei de Cotas o quadro dos estudantes que acessam a graduação em Teatro na UFMG sofreu alteração, tencionando a dinâmica anterior, já que a ampliação do ensino superior no Brasil tem trazido diversos avanços para a democracia e a elevação intelectual e econômica. E conforme José Dias Sobrinho (2013, p.120):

Estudantes pertencentes a estratos sociais mais baixos, em geral, receberam uma insatisfatória formação escolar nos níveis precedentes; por isso, quando chegam à educação superior se encontram em desvantagem em relação aos jovens que puderam construir um percurso formativo mais ajustado às exigências e dinâmicas da sociedade de economia global. 
O que tem se apresentado em nosso curso atualmente, é uma multiplicidade de estudantes e, consequentemente, de experiências no campo teatral, que ampliam o universo de estéticas e modos de fazer teatro na universidade, ao mesmo tempo que tenciona o processo de ensinoaprendizagem do teatro nos diversos componentes curriculares da graduação.

Trago a seguir um exemplo de um estudante de graduação que teve oportunidade de participar do Programa Institucional de Bolsa de Iniciação à Docência (PIBID) Teatro durante dois anos. Anderson, diferente da maioria dos estudantes do nosso curso, veio de outro estado e teve experiências artísticas anteriores que, não necessariamente, dialogam com a prova de habilidade específica. Por ser negro e oriundo de escola pública, teve acesso às vagas de cotista.

\section{PIBID Teatro: quando a trajetória de vida é parte do processo de ensino-aprendizagem em teatro}

Fui coordenador do PIBID Teatro na UFMG de 2011 a fevereiro de 2018, quando o programa teve seu fim ${ }^{2}$. Durante os sete anos na coordenação da área de Teatro contei com uma supervisora, que era professora de Arte da educação básica, e cinco bolsistas que eram estudantes da licenciatura em Teatro da UFMG. Os bolsistas podiam permanecer no projeto durante 24 meses, no máximo. Essa continuidade oportunizava o conhecimento do estudante e a aproximação deste com a realidade docente por estar imerso na escola em que o nosso projeto era parceiro: Escola Municipal Aurélio Pires.

O bolsista tinha que apresentar uma disponibilidade de $20 \mathrm{~h}$ semanais para integrar a equipe, tendo que ir à escola em duas manhãs por semana, além de participar das reuniões semanais às $6^{a}$ feiras comigo e a supervisora. Talvez, esse era um dos motivos que dificultou, em alguns

\footnotetext{
2 Falarei do PIBID até fevereiro de 2018, quando se encerrou o edital. O PIBID retorna em agosto de 2018 em todo país, agora com várias modificações.
} 
momentos, preencher as cinco vagas do projeto. Não descarto uma realidade apresentada em nosso curso de graduação que também dificultava o preenchimento das vagas: a pouco atratividade em ser professor de Arte no país, dada as condições salariais, das escolas, de políticas de valorização do magistério etc., além da dificuldade do curso apresentar a docência enquanto criação, já que a grande parte dos estudantes de Teatro vêm para a universidade na intenção de serem atores.

Apresento a trajetória de Anderson Ferreira do Nascimento, bolsista do subprojeto PIBID Teatro, que realizou seu percurso de formação no programa durante os anos de 2014 e 2015. Farei uso da abordagem de história de vida (JOSSO, 2004) em ressonância com o teatro.

Anderson vem de uma trajetória em escola pública - o que o aproximou da realidade dos jovens da Escola Municipal Aurélio Pires (EMAP), da qual nosso subprojeto era parceiro.

Além desse dado, Anderson é negro e militante das questões étnicoraciais, dado que também o aproxima dos alunos da EMAP. Porém, a questão étnico-racial não fazia parte, explicitamente, do currículo escolar, que ao não contemplar a discussão, acabava não promovendo o respeito à cultura e identidade do jovem negro.

Enveredando-se pela temática do Teatro $\mathrm{Negro}^{3}$, ressalto um aspecto que Anderson manteve frente às discussões com os jovens alunos: o teatro engajado negro.

Anderson, ao elaborar seu Trabalho de Conclusão de Curso da graduação em Teatro “An[coragem]: um educador negro a bordo", orientado por mim, faz uso de sua história de vida para compreender sua trajetória enquanto educador negro e dá início ao texto com a seguinte história:

Um dia me arrumando para ir à escola, minha avó me disse que eu deveria estudar muito porque esse sempre foi seu desejo. Era que seu pai lhe obrigava a

\footnotetext{
${ }^{3}$ Para maiores informações vale à pena um estudo sobre o Teatro Experimental do Negro (TEN), criado em outubro de 1944 no Brasil que em seu manifesto propunha-se a: "integrar o negro na sociedade brasileira; criticar a ideologia da brancura; valorizar a contribuição negra à cultura brasileira; mostrar que o negro era dotado de visão intelectual e dotar os palcos de uma dramaturgia intrinsecamente negra." (LIMA, 2010, p.83).
} 
trabalhar na roça desde criança e não lhe permitiu acesso aos livros. Analfabeta, ela admirava por demais quem sabia ler, pois, segundo ela, quem tinha esse privilégio sabia todas as histórias, podia ir em qualquer lugar sem se perder e ainda voltava para casa com histórias na bagagem para contar. Mas seu pai lhe dizia que era tempo perdido e que não adiantava muita insistência, pois seu caminho já era certo: trabalhar, ajudar nas despesas da casa, depois casar e servir ao marido. Ela casou com meu avô, porteiro do prédio que abriga a TV Cabo Branco, emissora filial da Rede Globo em João Pessoa/PB. Meu avô me mostrava as poucas fotografias das vezes que o chamaram para atuar como figurante no papel de negro escravizado nas séries e outros eventos da emissora. Disse que se ele empenha-se mais, um dia seria protagonista de uma dessas novelas. Mas sempre questionava que história ele podia contar. (NASCIMENTO, 2017, p. 07)

Reconhecer-se negro e narrar sua história de vida foi dado importante na trajetória de Anderson, afinal, ao ser professor e lidar com tantos outros jovens negros, poderia permitir que sua história se aproximasse dos jovens, ampliando para alguns as possibilidades de inserção social e conquistas intelectuais, uma vez que grande parte dos alunos de escolas públicas não têm o ensino superior como uma possibilidade de estudos e formação.

Ao procurar pela iniciação teatral em sua vida, Anderson se lembra que por ter desenvolvido gagueira entre os 7 e 8 anos, após ter se mudado com sua mãe de João Pessoa/PB para Santos/SP, foi indicado por uma fonoaudióloga a procurar um curso de teatro na nova cidade.

Começou a frequentar as aulas de teatro oferecidas pela igreja católica e na apresentação de final de ano, sua mãe teve que custear o figurino.

No dia o Teatro Municipal Brás Cubas estava lotado. Da minha família recordome que estavam na plateia minha mãe, minha tia e meus primos. Foi a única vez que elas se sentaram em uma poltrona no teatro. Até porque no ano seguinte eu não conseguiria ir adiante com as aulas. A turma entraria em mais um processo de montagem e minha mãe não daria conta de comprar outro figurino e os demais materiais. (NASCIMENTO, 2017, p. 13)

Após chorar muito, Anderson comenta que, ainda criança, começou a compreender as dificuldades para acessar determinados lugares sociais, já que era oriunda de uma família de baixa renda econômica. Enquanto educador penso ser importante dizer sobre o tipo de teatro que é praticado em várias instituições e o peso que recai sobre as famílias na compra de 
materiais, tal como o figurino da apresentação de Anderson. Daí... "o teatro começou a ser um sonho..." (idem).

Mas os encontros são possíveis, em quaisquer condições financeiras. Anderson tem uma tia que morava próxima a Santos, em Praia Grande/SP, onde possui a escola de samba Guaratude. No ano de 2011, quando adolescente, uma amiga dessa cidade, sabendo que ele se interessava por teatro, o convidou para participar da comissão de frente da escola de samba. A partir dos ensaios foi se interessando pelo trabalho da escola de samba e naquele espaço, percebeu que a maioria das pessoas eram negras e ocupavam funções sociais que exigem pouca escolaridade (faxineiras, porteiros, lavadeiras, cozinheiras). Ele percebe, com o olhar de agora, que o Guaratude foi o seu primeiro espaço de resistência, podendo se fortalecer e dialogar com pessoas que eram próximas ao seu contexto social, mas que poderia romper essa barreira e atravessar a trama social.

Ao decidir prestar o vestibular para o curso de Teatro na Universidade Federal de Minas Gerais, conta de seu estranhamento com esse novo "universo", pois "percebi que as minhas referências pessoais e artísticas não correspondiam ao que a universidade estava disposta a me ensinar. O corpo, os autores e a dinâmica pedagógica eram distantes das memórias que eu trazia na bagagem”. (NASCIMENTO, 2017, p.19).

Durante seu percurso na graduação em Teatro, conseguiu auxílio moradia e alimentação pela universidade e integrou o PIBID, que é um programa que investe na formação do professor, incentivando-o a conhecer durante o período da graduação, a realidade do professor da escola pública.

Assim, em minha função de coordenador do PIBID Teatro, conhecendo um pouco a trajetória de vida e interesses estéticos dos jovens graduandos, questionei-os sobre algum repertório dramatúrgico que versava sobre a temática do negro na sociedade. Anderson, assim como seus outros colegas, mostraram-se pouco ambientados com textos de teatro que trazem o negro e sua cultura como centro da discussão. Reportei-me então ao texto 
Chico Rei, da dramaturga Adélia Carvalho4, do qual eu já havia encenado quando residia em Ouro Preto/MG e apresentei-o aos licenciandos, que demonstraram grande interesse em propor um exercício cênico que partisse da obra de referência.

Em síntese, Chico Rei $^{5}$ conta a história de um negro africano chamado Galanga, que foi capturado e trazido ao Brasil pela corte portuguesa, batizado posteriormente de Francisco. Teve suas filhas e esposa jogadas ao mar durante o trajeto de vinda ao nosso país, restando-lhe apenas o filho. Ao chegar em Ouro Preto, antiga Vila Rica, trabalhou como escravo em uma mina de ouro e com o tempo conseguiu comprar sua alforria, do seu filho e de todos os seus súditos do tempo em que era rei no Congo. Posteriormente, criou a irmandade em honra a Santa Efigênia, além de ajudar na construção da igreja de Nossa Senhora do Rosário.

O tema e período histórico abordado no texto veio a calhar com a temática escolar daquele semestre: o barroco mineiro. Por parte de Anderson havia então o interesse de proporcionar uma reflexão acerca da escravidão e da contribuição da cultura de matriz africana para a formação da sociedade brasileira.

Aproveitamos esse pretexto para dar início às primeiras práticas com o teatro e normas da Lei 10.639/2003 que versa sobre a História e Cultura Afro - Brasileira e Africana.

\footnotetext{
${ }^{4}$ Adélia Carvalho é professora do curso de graduação em Teatro da Universidade Federal do Macapá, dramaturga e encenadora, além de fundadora da Cia. Teatral As Medéias. É autora do Blog Adélia Carvalho, disponível em http://adelia.carvalho.zip.net/arch2015-0726_2015-08-01.html acessado em 28/07/2015 às 10:49 h.

5 O texto dramático de Adélia Carvalho é baseado no livro Chico Rei de Agripa Vasconcelos (1966), e conta a história do Rei Galanga, nascido no Congo, que, capturado com toda sua família e sua corte por portugueses, foi escravizado aqui no Brasil. No caminho, perdeu sua esposa a Rainha e sua filha, ambas jogadas ao mar pelos capitães do navio. Ao chegar em Vila Rica, hoje Ouro Preto, somente com seu filho Muzinga, trabalhou em uma mina de ouro. Com o tempo de trabalho dobrado, conseguiu comprar sua alforria, a do seu filho e ainda obter uma mina, para aos poucos conquistar a alforria dos outros companheiros. Assim criou uma irmandade em honra de Santa Efigênia, além de construir a Igreja de Nossa Senhora do Rosário e por fim ser coroado rei novamente. Preparando a an[coragem] nesse novo mundo que era a licenciatura em Teatro, uma das nossas maiores dificuldades em desenvolver o trabalho foi o início de conversa, o "por onde" iríamos começar. Responsáveis por isso, nosso trabalho de formação começou desde as reuniões de planejamento, quando tínhamos que, muitas vezes, defender o tema e compartilhar materiais até então desconhecidos pelos nossos companheiros de trabalho, brancos.
} 
Nesse âmbito, Anderson e os demais pibidianos foram à biblioteca da escola procurar saber se possuía livros de temática negra ${ }^{6}$ nas prateleiras e por que eles não ocupavam os lugares de destaque no "canto da leitura", tal como outras temáticas hegemônicas. A bibliotecária disse que, mesmo com os kits disponibilizados pela prefeitura de Belo Horizonte, poucos são os professores que desenvolviam um trabalho com esse tema e que alguns esperavam chegar novembro, mês em que é relembrado o dia da consciência negra.

Foi eleita a turma do $7^{\circ}$ ano para iniciarmos as discussões. No primeiro encontro, introduzindo o tema, optamos pelo jogo tradicional $\mathrm{O}$ rei mandou. Os pibidianos observaram que os alunos traziam muitas palavras de ordem, dando a entender ser de proximidade dos adolescentes. Depois, na roda conversa proposta no final de aula, perguntaram: "O que é um reino? Qual o dever de um rei em um reino? Fora do reino, o rei continua rei? Atualmente existem reinos? Se você fosse rei, o que você faria?" Poucos alunos responderam. A voz saia bem baixa e com muita timidez. Os exemplos de reinos mais citados foram o Brasil, a cidade e a escola. Todos os "reis" desses lugares eram considerados pelos alunos "maus", por "roubar o dinheiro das pessoas", "deixar as pessoas com fome" e "deixar as pessoas presas". Ao ser questionamento sobre o que fariam se fossem reis e rainhas, disseram que não seriam maus e acabariam com a violência e a fome. A partir daí foi dito aos alunos que iriam desenvolver, ao longo do semestre letivo, a história de um rei.

CORO - Onde estamos?

NARRADORA - Na África, no Congo, onde Galanga viveu!

CORO - Onde?

NARRADORA - Onde todos são negros, e os navios portugueses desembarcam todos os dias para levar negros como escravos...

CORO - Onde?

NARRADORA - No início eram levados apenas os criminosos condenados, mas a sede pela força dos negros era cada vez maior!

CORO - Onde?

\footnotetext{
${ }^{6}$ Segundo Eduardo de Assis Duarte, através do artigo Literatura Afro-brasileira em foco: um conceito em movimento, para identificar os textos correspondentes a esse tipo de literatura, é necessário observar o tema, a linguagem, o público leitor e, principalmente, o ponto de vista autoral. (DUARTE, 2011)
} 
NARRADORA - Onde só tem negro!

CORO - Onde?

NARRADORA - Onde todos são negros!.

(CARVALHO, 2005, p.1)

Ao apresentar ao grupo de adolescentes o diálogo inicial do texto Chico Rei, Anderson se deparou com um grande desconhecimento sobre a temática.

Decidimos, a partir de então, que os licenciandos iriam caracterizados como personagens, a fim de provocar os alunos com imagens e discussões acerca do potencial da encenação. $\mathrm{Na}$ aula seguinte, decidiram receber os alunos na sala de aula com uma disposição não convencional e avisaram que a aula daquele dia seria conduzida por outras pessoas.

Ao sair da sala, Anderson, Ana (pibidianos) e a professora Mônica (supervisora) ouviram os seguintes comentários: "são eles mesmos, estão loucos". Os adolescentes, ainda não habituados com aulas de teatro, desconheciam essa convenção teatral.

Em seguida a Mônica recebe um pergaminho pela janela, entregue por Ana, que dizia: "Senhores, hoje vocês terão uma visita ilustre. Preparem-se para receber o Rei". A assistente do rei, com um turbante, abre a porta e pede para que todos fiquem de pé. Até que o rei entra na sala trajado com uma bata congolesa e uma coroa ornada com diversas fitas de cetim, se apropriando e fazendo alusão a indumentária da realeza das irmandades do rosário.

Houveram por parte dos alunos alguns estranhamentos. "Onde estão os trompetes ao invés de atabaque e chocalhos? E por que uma assistente do rei usa turbante ao invés de roupas luxuosas?" - foram alguns dos questionamentos apresentados.

Ao longo da sequência das aulas, várias discussões foram promovidas junto dos alunos, principalmente o entendimento sobre reinados e a cultura africana. Os alunos puderam compreender e empreender ações que revelaram como temos influências de nossos antepassados negros que ajudaram na formação de nossa matriz cultural. 
No início houve uma resistência, por parte dos alunos, para entrarem no jogo: "Não é um rei", diz um aluno. Aos poucos começam a interagir questionando o nome do rei, de que lugar ele veio e por que ele se vestia daquela forma. O rei, como um griot, contou sua história fazendo-se de Rei Galanga - o pré-texto do nosso processo. Os alunos ficaram atentos à contação de história e observamos que era o drama (CABRAL, 2006) era um método potente a ser utilizado com aquela turma.

\footnotetext{
Em seguida, o rei sugeriu que os alunos criassem, coletivamente, um reino e distribuiu vários títulos aos alunos com o nome dos personagens da peça. No fim da aula, o rei passou sua coroa para um aluno negro que iria representá-lo. Para a despedida do rei, propusemos um cortejo, também com a intenção de introduzir o exercício do cardume. Depois da partida, voltamos como professores e ouvimos: "Cadê o rei e a assistente?" "Podiam vir mais vezes, eles são mais legais". (NASCIMENTO, 2017, p. 35)
}

O uso do professor-personagem possibilitou uma aproximação dos pibidianos com os adolescentes, além de possibilitar com que os professores em formação exercitassem seu repertório atoral em sala de aula - uma vez que também são atores.

Essa primeira experiência na sala de aula com o teatro e a Lei 10.639/03 indicaram algumas aproximações da trajetória de vida do professor em formação com a temática etnicorracial na escola.

\section{Considerações Finais}

As licenciaturas de todo país estão incumbidas, através da Resolução $\mathrm{n}^{\mathrm{o}} 2$ de 1 de julho de 2015 pelo Conselho Nacional de Educação a organizar o currículo com o mínimo de 3.200 horas, além de garantir conteúdos específicos em temáticas diversas como direitos humanos, diversidades etnicorraciais, de gênero, sexual, religiosa etc.

Penso que, na condição de formação de outros professores, há um rico potencial ao abordarmos a história de vida dos nossos estudantes para, em consonância com nossa área de conhecimento, o teatro, aproximar história de vida à história das lutas dos grupos excluídos da sociedade. 
Afinal, o que se espera é a construção de uma nação em que as condições de vida e oportunidade sejam iguais para todas as pessoas, uma vez que vivermos numa democracia em que a diversidade deve valorizada e respeitada.

\section{REFERÊNCIAS}

BRASIL. Lei 10.639/2003 que versa sobre a História e Cultura Afro Brasileira e Africana. $\quad$ Disponível em: $<$ http://www.planalto.gov.br/ccivil_03/leis/2003/l10.639.htm $>$ Acessado em 10/04/2018.

BRASIL. Lei 12.711 que dispõe sobre o ingresso nas universidades federais e nas instituições federais de ensino técnico de nível médio. Disponível em: $<$ http://www.planalto.gov.br/ccivil_03/_ato20112014/2012/decreto/d7824.htm> Acessado em 10/04/2018.

CABRAL, Beatriz. Drama como método de ensino. SP: Hucitec, 2006.

CARVALHO, Adélia Aparecida da Silva Carvalho. Chico Rei. Texto não publicado. 2004.

DIAS SOBRINHO, José. Educação Superior: bem público, equidade e democratização. Avaliação. Campinas, v.18, n.1, p.107-126, mar. 2013. EISNER, Elliot. Educating Artistic Vision. New York: Maccmillan, 1972. JOSSO, Marie-Christine. Experiências de vida e formação. São Paulo: Cortez, 2004.

LIMA, Evani Tavares. Um olhar sobre o Teatro Experimental do Negro e do Bando de Teatro Olodum. Tese de Doutorado (Programa de Pós-Graduação em Artes). Unicamp, Campinas, 2010.

NASCIMENTO, Anderson Ferreira. An[Coragem]: um educador negro a bordo. Trabalho de conclusão de curso. (Graduação em Teatro). Universidade Federal de Minas Gerais, Belo Horizonte, 2017.

Recebido em agosto de 2018. Aprovado em outubro de 2018. Publicado em dezembro de 2018. 